\title{
Proceeding
}

Supplementary Issue: Spring Conferences of Sports Science. Costa Blanca Sports Science Week, 26-28 April 2018. Calpe. Alicante, Spain

\section{Design and validation of a psychomotor profile evaluation scale in early childhood education}

\author{
JOSÉ INIESTA AVILÉS, FRANCISCO JOSÉ BORREGO BALSALOBRE \, GUILLERMO FELIPE LÓPEZ \\ SÁNCHEZ, ARTURO DÍAZ SUÁREZ
}

Faculty of Sports Sciences, University of Murcia, Spain

\begin{abstract}
The lack of evaluation scales of psychomotricity in Early Childhood Education that need in the motor development by evolutionary stage and present a reduced extension of items raises the need to stress on this aspect. The objective of the present study was to design and validate a psychomotor profile evaluation scale in preschool children aged from 3 to 5 years old. The evaluation scale is based on 17 items grouped in 7 dimensions. The content of the scale was validated through the considerations of 6 expert judges, as well as the validity of understanding through 10 preschool teachers. In the same way, a pilot study was carried out, in which the scale of evaluation was applied to 77 participants who were 3, 4 and 5 years old of Early Childhood Education of the "Primary and Secondary Education School Jacinto Benavente" and "Private Center of Education Monteazahar" located in Murcia. The Aiken V values in the content assessment reflected an average score of 0.777 for most items on the three scales, which had to be revised and modified. The students of the school "Jacinto Benavente" showed better ratings than in the "Monteazahar" school. Besides, it was observed that the results among 4-year-old students were the highest versus 3 and 5 years old respectively. As the first phase of the validation process, this evaluation scale must carry on developing until it obtains values that guarantee its purpose. Key words: PSYCHOMOTOR PROFILE, PSYCHOMOTRICITY, CHILD EDUCATION, EVALUATION SCALE, VALIDATION.
\end{abstract}

\section{Cite this article as:}

Iniesta Avilés, J., Borrego Balsalobre, F., López Sánchez, G., \& Díaz Suárez, A. (2018). Design and validation of a psychomotor profile evaluation scale in early childhood education. Journal of Human Sport and Exercise, 13(2proc), S421-S431. doi:https://doi.org/10.14198//ihse.2018.13.Proc2.26

Corresponding author. Faculty of Sports Sciences, University of Murcia, Spain.

E-mail: franborrego@um.es

Supplementary Issue: Spring Conferences of Sports Science. Costa Blanca Sports Science Week, 26-28 April 2018. Calpe. Alicante, Spain.

JOURNAL OF HUMAN SPORT \& EXERCISE ISSN 1988-5202

(c) Faculty of Education. University of Alicante

doi: 10.14198/jhse.2018.13.Proc2.26 


\section{INTRODUCTION}

Within the education field, psychomotricity becomes increasingly important for the personal development of the child and therefore must be included in the early Childhood Education curriculum. According to Garcia \& Berruezo (1994), psychomotricity is the most significant way to promote the development, evolution and preparation for the students' acquisition of learning from the early Childhood Education stage.

As Gómez-Marmol, López and Sánchez Álcaraz (2015) state, there exists a broad range of understandings of psychomotricity on which a large variety of theories and scientific approaches (as well as practices and methodologies) are based. For some authors, psychomotricity implies the interrelation between the neuromotor and the psychic functions on human beings (García \& Martínez, 1991). However, other authors allude to the set of techniques aimed at an overall development which, drawing from the education of movement and gesture, make it possible to achieve the symbolic function and the proper interaction with the environment (Maganto \& Cruz, 2012).

To be able to evaluate psychomotricity, several instruments for measuring and evaluating the psychomotor functions have emerged over the last century and beginning of the present one. For the evaluation of the psychomotor development, these instruments and evaluation scales (Oseretsky Test of Motor Proficiency (1930), Bender-Gestalt test (1938), Denver Developmental Screening test (1967), Bayley Scales of Infant Development (1969), Kiphard-Schilling Body Coordination test (1976), Picq and Vayer's Psychomotor tests (1977), Da Fonseca Psychomotor Observation or Da Fonseca's Psychomotor Battery (1985), Pyfer's test (1990), Evaluation Scale of Psychomotricity in Preschool (1990), Secadas' Observational Developmental Scale (2005), and Ulrich Test of Gross Motor Development (2000) among others) have been used in numerous studies and researches, in which attempts to evaluate the students' psychomotor profile have been made so that they may prove helpful to offset shortfalls and improve the motor development or to compare them with other parameters (Andrade, A., Bernardi, C., Guerra, L. \& Oliveira S., 2004; Fernández, 1996; Garaigordibil, 1999; Garaigordibil \& Amigo, 2010; Noguera \& García, 2013; Noguera, Herazo \& Vidarte, 2012; Valdés, 2003). Such studies are also crucial with regard to the students' achievement of a good overall education, especially in early Childhood Education (De La Cruz \& Mazaira, 1990).

The singular importance of the psychomotor development from birth makes it essential to rely on standardised evaluation and tracking parameters of such development. Besides, the lack of contextualisation and the absence of appropriate instruments for the evaluation of psychomotricity in early Childhood Education, which may be needed in the motor development by evolutionary stage and which present a reduced extension of items, suggests the need to stress on this aspect. For these reasons, by addressing different development scales such as the Peabody Developmental Motor Scale, the Gesell Child Developmental Age Scale and the Brunet-Lézine Early Childhood Psychomotor Development Scale (1978), efforts have been made to create an instrument with a reduced extension of items, easy to apply and accurate in terms of both the students' evolutionary stage and in the pattern of the items. In turn, the different characteristics concerning the specification of a test established by Mathieu (1999) have been met.

In such way, the main objective of the study was to design and to validate a psychomotor profile evaluation scale in preschool children from 3 to 5 years. Secondarily, it was intended to prove the validity of content of the instrument and its understanding and, finally, to conduct a pilot study of the evaluation of the psychomotor profile in children from 3 to 5 years. 


\section{MATERIALS AND METHODOLOGY}

\section{Participants}

The sample in this research was constituted by three types of participants.

For the study of the validity of content, there were six expert judges among whom it was sought that they met the following requirements: teaching staff experts in psychomotricity with at least two publications in highyield journals within such field and with more than five years of experience in the area.

For the study of the validity of understanding, there was a panel of ten teachers of early Childhood Education. Such sample was both intentionally and randomly selected among the different members of the early Childhood Education teaching staff from the centres "Preschool and Primary Education School Jacinto Benavente", located in the town of Alcantarilla (Murcia), and "Private Centre of Education Monteazahar", located in the town of Torres de Cotillas (Murcia). All of them had more than five years of teaching experience.

On the other hand, the instrument was introduced to 77 early Childhood Education students aged 3, 4 and 5 from the centres "Preschool and Primary Education School Jacinto Benavente", located in the town of Alcantarilla (Murcia) and "Private Centre of Education Monteazahar", located in the town of Torres de Cotillas (Murcia). In the first centre 32 students were evaluated, whereas 45 students were evaluated in the second one. Overall, 27 students aged 3, 27 students aged 4 and 23 students aged 5 could be counted between both centres. The students were chosen at random from among those who presented their parents or tutors' informed consent. These students also took two weekly psychomotricity lessons of 60 minutes each.

\section{Procedure}

The implementation of the design and validation of the scale used in the research was developed in five stages, following Carretero-Dios and Pérez $(2005,2007)$. The first stage involved conducting a literature search on the area of the object of study, which reflected the lack of evaluation instruments of psychomotricity in early Childhood Education that were accurate and that had a reduced number of items (10-20).

In the second stage, the design of the evaluation scale was carried out, focused on and grouped according to the age of 3, 4 and 5 years. A first design with 21 items per age scale was made, which was sent for a preliminary assessment by expert judges $(n=6)$. The instrument consisted of a brief introduction where the aim of the scale, its use, the way to evaluate each item and the materials needed for its implementation were explained. Next, a block of questions referring to socio-demographic data was added which recorded data such as the age in months, size, weight, gender, date of birth and measurement date. The remaining items were organised into three columns (one per age) and into three blocks, with different dimensions containing one or more items in each one.

In the third stage, the validity of content was carried out, defined as the degree to which a test properly represents what has been made (Thomas \& Nelson, 2007; Wiersma, 2001). To do so, the participation of a panel of expert judges was required $(n=15)$. Finally, the response of six judges was received, thereby forming the final number of expert judges. Such judges performed both a qualitative and quantitative valuation of the instrument focusing on the items which constituted the scale and on its overall valuation. Likewise, they were requested to evaluate the content of the initial information of the scale. The variables that were taken into consideration by the judges to analyse the validity of content of the instrument were the following: 
a) Degree of suitability. The expert judges were requested to value the suitability of each item constituting the scale both at quantitative and qualitative level (Likert type scale, from 1 to 10). Furthermore, they had to make any relevant comment with the purpose of giving an alternative or correcting any aspect related to the instrument.

b) Degree of attachment to the object of study. It was recorded to which extent each of the items should be part of the scale. For this purpose, the expert judges were requested to conceptually value the importance of each item on an independent manner. Thereupon, they pointed whether the items should or should not be part of the questionnaire, and their degree of attachment to the instrument ( $0=$ not suitable, $10=$ very suitable).

c) Degree of accuracy at the level of definition and understanding. It was recorded the degree of accuracy in the definition and formulation of each item by requesting the expert judges to point the degree of understanding of each instrument's item independently ( $0=$ not suitable, $10=$ very suitable).

The research team set the following criteria from the valuation of the items by the panel of expert judges:

- The items described by the expert judges as having more than three objections in the qualitative valuation of the design and those having a valuation of Aiken $V$ below 0,7 would be removed.

- The items described by any expert judge as having any issue in their formulation and/or those having a valuation of Aiken $V$ between 0,70 and 0,80 would be modified.

- The items having a valuation of Aiken $V$ over 0,9 would remain the same.

In the fourth stage, the responses of each of the six expert judges were construed, followed by a change of some components of the scale. Bearing in mind the view expressed by the expert judges, several items were modified and a new one was formed, remaining a total of 17 items and thus constituting the "Evaluation Scale of Childhood Psychomotricity" (PSM I). In this stage, to get the quantitative valuation of the expert judges, the Aiken $V$ was calculated.

In such stage, the validity of understanding was also carried out and analysed by a panel of ten early Childhood Education teachers. In that process, the formulations of the items were presented to the teachers in order to verify the existence of any difficulty in their understanding. To this effect, the degree of understanding of each item was valued taking into consideration the teachers' doubts, suggestions or the possible lack of comprehension from their reading. Then, their responses were analysed based on the analysis of the high response rate where it was shown that all items were below $90 \%$, being likewise quite valid according to Zhu, Ennis and Chen (1998).

Finally, a pilot study was carried out. After having first informed the school board and the teaching staff from both centres of the objectives of the study and of the use of the data gathered from the measurements, the consent to conduct the study with the students of both centres was obtained. The sample selection was made at random based on the students who had the informed consent by their parents or by the tutors of the centre where the study was conducted. Following the selection of the sample, the "Evaluation Scale of Childhood Psychomotricity (PSM I)" was introduced to the students during school hours. Then, a measurement was performed in each centre and, during that time, a researcher and two assistants evaluated the students with no issues encountered during the process. 


\section{Statistical analysis}

For the data processing, Microsoft Excel 2010 and the statistical package SPSS 21.0 for Windows have been used. The Aiken V test was used for the calculation of the validity of content (Penfield \& Giacobbi, 2004). Besides, the internal consistency of each of the three scales was verified by means of the Cronbrach's Alpha test (Conroy \& Metzler, 2003). Eventually, the descriptive statistics of each item were calculated (mean and standard deviation), and the contrast statistics were performed (Student's $t$-test for independent samples and Bonferroni Correction for post hoc analysis of an element in ANOVA). The level of significance was set at $p \leq 0,05$.

\section{Instrument}

The final Evaluation Scale of Childhood Psychomotricity (PSM I) is aimed at measuring the psychomotor profile in subjects aged 3, 4 and 5 . It is made of 17 items grouped in seven dimensions which, in turn, are found within three areas as follows: Gross Motor, Fine Motor and Body Schema. Also, the socio-demographic dimension comprises four items: gender, age (in months), school year, size and weight.

Table 1. Areas and dimensions of the instrument.

\begin{tabular}{|c|c|c|}
\hline Area & Dimension & Explanation \\
\hline \multirow{4}{*}{ Gross Motor } & $\begin{array}{l}\text { Locomotion } \\
\qquad \text { (LO) }\end{array}$ & $\begin{array}{l}\text { Its objective is to evaluate the subject's ability to } \\
\text { move or to move around from one place to another. } \\
\text { The effectiveness in motion movements such as } \\
\text { walking or running in different directions as well as } \\
\text { tiptoeing are reckoned. In turn, the level of } \\
\text { coordination and efficiency in such movements is } \\
\text { also evaluated. }\end{array}$ \\
\hline & $\begin{array}{l}\text { Leg } \\
\text { coordination } \\
\text { (LC) }\end{array}$ & $\begin{array}{l}\text { The objective of the LC is to evaluate the subject's } \\
\text { ability to jump statically in different directions and } \\
\text { heights. }\end{array}$ \\
\hline & Balance (BL) & $\begin{array}{l}\text { The objective of the BL is to evaluate the subject's } \\
\text { ability to maintain the static stability of their bodies } \\
\text { during the realisation of a motor task. }\end{array}$ \\
\hline & $\begin{array}{l}\text { Arm } \\
\text { coordination } \\
\text { (AC) }\end{array}$ & $\begin{array}{l}\text { The objective of the AC is to evaluate the subject's } \\
\text { ability to handle surrounding objects by grabbing, } \\
\text { throwing, catching or bouncing them. }\end{array}$ \\
\hline Fine Motor & $\begin{array}{l}\text { Hand-eye } \\
\text { coordination } \\
(\mathrm{HEC})\end{array}$ & $\begin{array}{l}\text { The objective of the HEC is to evaluate the subject's } \\
\text { ability to use their visual perceptual skills in the } \\
\text { realisation of manual tasks by using smaller tools. }\end{array}$ \\
\hline \multirow{2}{*}{ Body Schema } & $\begin{array}{l}\text { Segmental } \\
\text { distinction } \\
\quad(\mathrm{SD})\end{array}$ & $\begin{array}{l}\text { The objective of the SD is to evaluate the subject's } \\
\text { ability to recognise the different body parts in their } \\
\text { own body, in a drawing and in other people. }\end{array}$ \\
\hline & Laterality (LA) & $\begin{array}{l}\text { The objective of the LA is to register the subject's } \\
\text { inclination to use one hand over the other during the } \\
\text { development of certain tests of the instrument. }\end{array}$ \\
\hline
\end{tabular}


In Table 1, all dimensions as well as what it is sought to evaluate in each one is clarified. The researcher evaluated the students' psychomotricity by the use of a Likert type scale from 1 to 4 options in order to avoid the central tendency error, and such evaluator also had to decide on different options to reduce the centralisation of the responses. Regarding the route of administration, it is applied following the protocol established by the scale.

Within the Gross Motor block, the dimensions of Locomotion (items 1.1, 1.2 and 1.3), Leg coordination (items 2.1 and 2.2), Balance (items 3.1and 3.2) and Arm coordination (items 4.1, 4.2 and 4.3) can be found. Within the Fine Motor block, the dimension of Hand-eye coordination is found (items 5.1, 5.2, 5.3, 5.4 y 5.5). Finally, within the Body Schema block, the dimension of Segmental distinction (item 6.1) and Laterality (item 7.1) are found.

The creation of this scale intended to avoid the social desirability by trying to clarify the function of each item for its evaluation and to reduce the evaluator's free interpretation as much as possible. To rate the responses, it was stipulated that they ought to be analogue rather than dichotomous or polytomous since the intention was to limit the evaluator's responses to some restrained values. The reliability of the subscales by different age, measured by means of Cronbrach's Alpha test, revealed the following values: 3 years $(\alpha=0,836), 4$ years $(\alpha=0,450)$ and 5 years $(\alpha=0,806)$.

\section{RESULTS}

\section{Results of validity of content}

Results of validity of content, overall evaluation

With regard to the overall evaluation of the content of the 3 year old scale by the expert judges, the results showed that 12 items (items 1.1, 1.2, 1.3, 2.1, 2.2, 3.2, 4.1, 5.1, 5.2, 5.3, 5.4, and 6.1) reflected an Aiken V of 0,777 , being it the lowest value obtained. The remaining items obtained a value of 0,888 , being the highest score obtained since they were very well valued by the judges. These results also coincided with the ones obtained in the valuation of the degree of accuracy and formulation of items. Besides, these outcomes of the 3 year old scale are reflected in the ones obtained in the 4 year old scale in relation to the items and valuations in the Aiken V. Regarding the overall valuation of content of the 5 year old scale, the results showed that 8 items $(1.2,1.3,2.2,4.1,5.2,5.3,5.4$, and 6.1) obtained an Aiken $V$ of 0,777 , being it the lowest value obtained of all items. The other items got a value of 0,888 , being the highest score obtained since they were well valued by the expert judges. These results corresponded with the ones obtained in the valuation of the degree of accuracy and formulation of items.

Results of validity of content, qualitative evaluation

Taking into account the expert judges' qualitative valuation of the 3 year old scale, the items 2.2, 3.2, 5.1, $5.2,5.3$ and 5.4 were either redefined or changed. Next, considering their qualitative valuation of the 4 year old scale, the items 2.2, 3.2, 5.1, 5.2, 5.3 and 5.4 were either redefined or changed. Finally, taking into consideration their qualitative valuation of the 5 year old scale, the items 2.2, 3.2, 5.1, 5.2, 5.3 and 5.4 were either redefined or changed. Eventually, in response to these results, the item 5.5 was added to the 3,4 and 5 year old scales respectively.

\section{Descriptive and contrast analyses}

The following table includes the results delivered in the descriptive analysis of all the dimensions and items regarding their valuation (1-4), and the contrast analysis between the different age groups (table 2). The outcomes showed that in the 3 year old groups there were only 2 highly valued items, having the lowest 
numbers. Regarding the 4 year old groups, it was revealed that they had the larger and most valued number of items with a total of 9 items and 4 dimensions. As regards the results of the 5 year old groups, there were only 5 items with the maximum value on average and a total of one dimension.

Table 2. Comparative of analysed items between school years.

\begin{tabular}{cc|cccccccc}
\hline \multirow{2}{*}{ Item } & \multicolumn{3}{|c}{ 3 years } & \multicolumn{2}{c}{ 4 years } & \multicolumn{2}{c}{ 5 years } & \multicolumn{2}{c}{ ANOVA } \\
\cline { 3 - 9 } & & $\mathbf{M}$ & SD & M & SD & M & SD & F & Sig \\
\hline $\mathbf{1}$ & & 9,93 & 2,66 & 11,04 & 1,19 & 11,00 & 2,04 & 2,484 & 0,090 \\
& $\mathbf{1 . 1}$ & 3,33 & 1,11 & 3,67 & 0,68 & 3,65 & 0,78 & 1,212 & 0,303 \\
& $\mathbf{1 . 2}$ & 3,33 & 1,14 & 3,96 & 0,19 & 3,87 & 0,63 & 5,216 & $0,008^{* \wedge}$ \\
& $\mathbf{1 . 3}$ & 3,26 & 1,20 & 3,41 & 1,01 & 3,48 & 1,04 & 0,269 & 0,765 \\
$\mathbf{2}$ & & 6,74 & 1,85 & 7,00 & 1,36 & 6,43 & 1,47 & 0,794 & 0,456 \\
& $\mathbf{2 . 1}$ & 3,78 & 0,80 & 3,93 & 0,27 & 3,35 & 1,15 & 3,406 & $0,038 \#$ \\
& $\mathbf{2 . 2}$ & 2,96 & 1,37 & 3,07 & 1,33 & 3,09 & 1,31 & 0,068 & 0,935 \\
$\mathbf{3}$ & & 6,22 & 1,83 & 7,11 & 1,42 & 6,61 & 1,37 & 2,194 & 0,119 \\
& $\mathbf{3 . 1}$ & 2,89 & 1,15 & 3,37 & 0,88 & 2,87 & 1,10 & 1,914 & 0,155 \\
& $\mathbf{3 . 2}$ & 3,33 & 1,04 & 3,74 & 0,81 & 3,75 & 0,69 & 1,929 & 0,153 \\
$\mathbf{4}$ & & 9,52 & 2,38 & 7,96 & 2,03 & 9,91 & 1,56 & 6,597 & $0,002^{*} \#$ \\
& $\mathbf{4 . 1}$ & 3,74 & 0,81 & 3,37 & 0,63 & 3,43 & 0,73 & 1,973 & 0,146 \\
& $\mathbf{4 . 2}$ & 3,33 & 1,00 & 2,48 & 1,16 & 3,74 & 0,54 & 11,542 & $0,001 * \#$ \\
& $\mathbf{4 . 3}$ & 2,44 & 1,40 & 2,11 & 1,37 & 2,74 & 1,39 & 1,288 & 0,282 \\
$\mathbf{5}$ & & 15,70 & 3,79 & 18,22 & 1,85 & 16,78 & 3,49 & 4,365 & $0,016^{*}$ \\
& $\mathbf{5 . 1}$ & 2,59 & 1,37 & 3,59 & 0,64 & 3,09 & 0,90 & 6,499 & $0,003^{*}$ \\
& $\mathbf{5 . 2}$ & 3,15 & 1,23 & 3,44 & 0,89 & 3,30 & 0,88 & 0,570 & 0,568 \\
& $\mathbf{5 . 3}$ & 3,26 & 1,02 & 3,89 & 0,32 & 3,78 & 0,67 & 5,632 & $0,005 * \#$ \\
& $\mathbf{5 . 4}$ & 3,81 & 0,48 & 3,74 & 0,53 & 3,52 & 0,90 & 1,351 & 0,265 \\
& $\mathbf{5 . 5}$ & 2,88 & 1,25 & 3,56 & 0,80 & 3,08 & 1,12 & 2,735 & 0,071 \\
& $\mathbf{6 . 1}$ & 3,89 & 0,58 & 4,00 & 0,00 & 3,87 & 0,46 & 0,717 & 0,492 \\
\hline
\end{tabular}

*Diferences between 3 and 4 years

Diferences between 3 and 5 years

\#Diferences between 4 and 5 years

The items with the highest score obtained in the 3 year old groups were the $6.1(3,89), 5.4(3,81)$ and 2.1 $(3,78)$. The items with the highest score obtained in the 4 year old groups were the $6.1(4,00), 1.2(3,96)$ and $2.1(3,93)$. The items with the highest score obtained in the 5 year old groups were the $6.1(3,87), 1.2(3,87)$ and $5.3(3,78)$. The items with the lowest score obtained in the 3 year old groups were the $4.3(2,44), 5.1$ $(2,59)$ and $5.5(2,88)$. The items with the lowest score obtained in the 4 year old groups were the $4.3(2,11)$, $4.2(2,48)$ and $2.2(3,07)$. The items with the lowest score obtained in the 5 year old groups were the 4.3 $(2,74), 3.1(2,87)$ and $5.5(3,08)$. The dimensions of Locomotion, Leg coordination, Balance and Hand-eye coordination had the highest scores in the 4 year old groups, whereas the Arm coordination dimension was the one with the highest score in the 5 year old groups.

Considering the Bonferroni Correction post hoc test, statistically significant differences were found in the item 1.2 , with the major variation coming between the groups of 3-4 years and 3-5 years respectively; in the item 
2.1 between the groups of 4-5 years; in the Arm coordination dimension between the groups of 3-4 years and 4-5 years respectively; in the item 4.2 between the groups of 3-4 years and 4-5 years respectively; in the Hand-eye coordination dimension between the groups of 3-4 years; in the item 5.1 between the groups of 34 years and in the item 5.3 between the groups of 3-4 years and 4-5 years, respectively.

Taking these valuations into consideration in table 2, it was observed that the highest results were found in the 4 year old groups against the 3 and 5 year old ones.

With regard to the results delivered in the descriptive analysis of all dimensions and items concerning their evaluation (1-4) and the contrast analysis between both centres, it seems that the students in the school centre "Jacinto Benavente" registered better ratings than the ones in the school centre "Monteazahar". As for the Locomotion dimension, the school centre "Monteazahar" had better results $(10,68)$ than the "Jacinto Benavente" $(10,56)$ in the overall score. Focusing on the items that constitute such dimension, just the item 1.3 presented better scores in the Monteazahar $(3,60)$, while the items 1.1 and 1.2 were best valued in the Jacinto Benavente. In the Leg coordination dimension, the Jacinto Benavente $(6,94)$ presented a better overall score than the Monteazahar (6,60). In relation to the Balance dimension, the overall score was best in the Jacinto Benavente $(6,69)$ than in the Monteazahar $(6,62)$. The Arm coordination dimension had best ratings in the Monteazahar both in the overall score and in the total of items. Next, the Hand-eye coordination dimension had best evaluations in the Jacinto Benavente both in the overall score and in the total of items.

Thus, taking note of the significance of the values, both school centres presented major differences in items 1.3, 2.2 and 3.2 when looking at the variation in their scores.

\section{DISCUSSION}

The aim of this study was to design and to validate a psychomotor profile evaluation scale in preschool children aged from 3 to 5 years old, to prove the validity of content of the instrument and its understanding as well as to conduct a pilot study applying such instrument. The results of the study reflected that the evaluation scale must be kept under review within the validation process, completing thus the first stage of the same.

Defining and setting the students' psychomotor profile can be helpful to identify abilities such as their least developed areas or potential forces as well as any signs found in the psychomotor field. In such way, it can also be used to figure out how the presence or the absence of a physical activity plan can affect the school children (Gomedio \& Maganto, 2000).

The design and the development of the instrument were elaborated following different stages as well as relying on the participation of a panel of expert judges (Carretero-Dios \& Pérez, 2005, 2007). Besides, the number of judges consulted resembled other similar studies (Gómez-Mármol, López, \& Sánchez Alcaraz, 2015; Sánchez-Alcaraz Martínez, Henarejos Aparicio, Gómez-Mármol \& Paredes García, 2016). The expert judges' contribution was vital for detecting errors and aspects needing improvement in the design of the instrument, changing then some items and reformulating their definition, content and adequacy. Regarding the validity of content, the judges' quantitative valuations revealed that most of the items from the three scales had an average score of Aiken $\vee 0,777$, implying that they should be revised and changed (Penfield \& Giacobbi, 2004). 
In turn, a panel of ten Childhood Education teachers completed a validity of understanding test which made it possible to identify their comprehension of the different items that formed the instrument. Lastly, a pilot study where such instrument was introduced was conducted in order to review both the valuations and the work done, and to ensure further progress in the validation process. In this way, the results indicated that the students from the school centre "Jacinto Benavente" had better ratings than those in the "Monteazahar": the "Jacinto Benavente" had better scores in 10 items against the "Monteazahar", with 6 items. Regarding the overall results of the dimensions of the scale, the school centre "Jacinto Benavente" had favourable outcomes in 3 of them (Leg coordination, Balance and Hand-eye coordination), while the "Monteazahar" performed positively in 2 dimensions (Locomotion and Arm coordination). Furthermore, the highest results were scored by the 4 year old groups against the 3 and 5 year old ones, respectively. In spite of the quest for accuracy in the development of the three scales by age, the 5 year old groups were expected to obtain higher results since the stage of motor development of students this age is far more advanced.

With regard to the limitations of the study, the following observations should be highlighted. First of all, the Cronbrach's Alpha value for the 4 year old scale registered very low numbers $(a=0,450)$ due to the fact that some items were not suitable for such age and therefore need revision. This matter correlates with the results of the ANOVA test of an element using the Bonferroni Correction post hoc test, where the highest ratings are found in the 4 year old scale rather than in the 5 year old one. Secondly, it is worth noting that the pilot study had a small sample size. On this basis, a much larger sample size must be collected for future researches continuing the validation process of this instrument, with the purpose of carrying out both the construct validity and the reliability analysis.

In turn, a second consultation with a larger panel of experts must be held, including the new changes made. In such way, the final aim is to establish an instrument which enables to classify the students' degree of psychomotricity and to monitor their progress lengthwise (Fernández, 1996; Valdés, 2003).

\section{CONCLUSIONS}

Following the presentation and discussion of the results, it is right to conclude that this evaluation scale needs to be reviewed. This is because the outcomes obtained in the validity of content reflect that there is a considerable amount of items which must be modified before continuing the validation process. Next, the students from the school centre "Jacinto Benavente" had better scores in 10 items against the students from the "Monteazahar", with better scores in 6 items. Apart from that, the best valued dimensions in the school centre "Jacinto Benavente" were Leg coordination, Balance and Hand-eye coordination. On the other hand, in the school centre "Monteazahar" the best valued dimensions were Locomotion and Arm coordination. With reference to the results in terms of age, the highest ones were scored by the 4 year old groups against the 3 and 5 year old groups, respectively. Finally, in order to carry out the construct validity and the reliability analysis of the instrument, it will be necessary for future researches to conduct a study which contains a larger sample size in terms of expert judges and students.

\section{REFERENCES}

Andrade, A., Bernardi, C., Guerra, L. \& Oliveira, S. (2004). Perfil psicomotor associado a aprendizagem escolar. Lecturas: Educación física y deportes, (79).

Brunet, O. \& Lezine, I. (1978). El desarrollo psicológico de la primera infancia. Madrid: Pablo de Río.

Carretero-Dios, H. \& Pérez, C. (2005). Normas para el desarrollo y revisión de estudios instrumentales. International Journal of Clinical Health Psychology, 5(3), 521-551. 
Carretero-Dios, H. \& Pérez, C. (2007). Standards for the development and the review of instrumental studies: Considerations about test selection in psychological research. International Journal of Clinical Health Psychology, 7, 863-882.

Conroy, D. y Metzler, J. (2003). Temporal stability of performance failure appraisal inventory ítems. Measurement in Physical Education and Exercise Science, 7(4), 243-261. https://doi.org/10.1207/S15327841MPEE0704_3

De la Cruz, M. \& Mazaira, M. (1990). Escala de evaluación de la psicomotricidad en preescolar. Madrid: TEA.

Fernández, N. (1996). Un programa de educación psicomotriz. Psicothema, 8(1), 77-88.

Garaigordobil, M. (1999). Evaluación del desarrollo psicomotor y sus relaciones con la inteligencia verbal y no verbal. Revista Iberoamericana de Diagnóstico y Evaluación Psicológica, 8(2), 1-36.

Garaigordobil, M., \& Amigo, R. (2010). Inteligencia: Diferencias de género y relaciones con factores psicomotrices, conductuales y emocionales en ni-os de 5 a-os. Interdisciplinaria, 27(2), 229-246.

García, J. A. \& Berruezo, P. P. (1994). Psicomotricidad y educación infantil. Madrid: CEPE.

García, J.A. y Martínez, P. (1991). Psicomotricidad y educación preescolar. (7ª Edición). Madrid. García Nuñez, editor.

Gomendio, M. \& Maganto, C. (2000). Eficacia y mejora del desarrollo psicomotor, el autoconcepto y la socialización a través de un programa de actividades físicas. Apunts, (61), 24-30.

Gómez-Mármol, A., López, M. F., \& Sánchez Alcaraz, B. J. (2015). Diseño, validación y aplicación de una Hoja de Observación para la Evaluación de la Psicomotricidad Acuática (HOEPA) en edad infantil. Sportis, Revista Técnico-Científica del Deporte Escolar, Educación Física y Psicomotricidad, 3(1), 270-292.

Maganto, C., \& Cruz, S. (2012). Desarrollo físico y psicomotor en la etapa infantil. Manual de psicología infantil: aspectos evolutivos e intervención psicopedagógica, 27-64.

Mathieu, W. (1999). Medición y Evaluación de la Educación Física. Universidad de Costa Rica.

Noguera, L. \& García, P. (2013). Perfil Psicomotor en Niños Escolares: Diferencias de Género. Ciencia e Innovación en Salud, 1(2), 108-113.

Noguera, L., Herazo, Y. \& Vidarte, J. (2012). Correlación entre perfil psicomotor y rendimiento lógicomatemático en niños de 4 a 8 años. Revista Ciencias de la Salud, 11(2), 185-194.

Penfield, R. D., \& Giacobbi Peter R, J. (2004). Applying a score confidence interval to Aiken's item content-relevance index. Measurement in Physical Education and Exercise Science, 8(4), 213-225. https://doi.org/10.1207/s15327841mpee0804_3

Sánchez-Alcaraz Martínez, B. J., Henarejos Aparicio, M. S., Gómez-Mármol, A. \& Paredes García, I. (2016). Diseño y validación del cuestionario sobre la psicomotricidad en el contexto educativo (CPCE). Trances, 8(2), 143-156.

Thomas, J.R. y Nelson, J.K. (2007). Métodos de investigación en actividad física. Barcelona: Paidotribo.

Valdés, M. (2003). Desarrollo Psicomotor de niños y niñas de 3 a 5 años de edad, que asisten a centros de educación pre-escolar de la ciudad de Talca. Revista iberoamericana de Psicomotricidad y Técnicas Corporales, (10), 87-95.

Wiersma, L.D. (2001). Conceptualization and development of the sources of enjoyment in youth sport questionnaire. Measurement in Physical Education and Exercise Science, 5(3), 153-177. https://doi.org/10.1207/S15327841MPEE0503_3

Zhu, W., Ennis, C. D., \& Chen, A. (1998). Many-faceted rasch modelling expert judgment in test development. Measurement in Psysical Education and Exercise Science, 2(1), 21-39. https://doi.org/10.1207/s15327841mpee0201_2 


\section{(c) (i) (3)}

This title is licensed under a Creative Commons Attribution-NonCommercial-NoDerivs 4.0 Unported License. 